\title{
Importance of Effective Retraction for Exposing Loose Areolar Plane in Suprafascial Deep Inferior Epigastric Perforator Flap Raising
}

\author{
Juan Enrique Berner ${ }^{1,2, \odot} \quad$ Ioannis Kyriazidis ${ }^{1} \quad$ Adam Blackburn $^{1}$
}

\author{
${ }^{1}$ Queen Victoria Hospital NHS Foundation Trust, East Grinstead, \\ United Kingdom \\ ${ }^{2}$ Kellogg College, University of Oxford, Oxford, United Kingdom
}

Indian J Plast Surg 2019;52:366-368

In recent years, perforator flaps have become an important tool in the reconstructive surgery armamentarium. In this technique, careful dissection of vascular perforators allows transfer of well-perfused tissue locally, regionally, and even distantly as free flaps. ${ }^{1}$ Even though the importance of adequate retraction has been emphasized in the past, ${ }^{2}$ this article presents a technical tip for suprafascial identification and dissection of perforators, particularly useful for deep inferior epigastric perforator flaps. Suprafascial flap raising usually involves dissecting through the plane between the fascia and the superficial adipose tissue until perforators are visualized. The senior author has noticed that standard upward

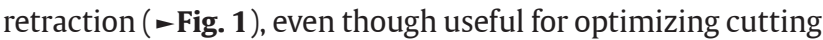
through tissues, can actually hide perforators behind the fascia as this is pulled up. Instead, if upward retraction is combined with gently pulling of the flap away from the surgeon, a loose areolar plane is exposed, aiding safe raising of the flap
Address for correspondence Juan Enrique Berner, MD, MSc, MRCS, Queen Victoria Hospital, Holtye Road, East Grinstead RH19 3DZ, United Kingdom (e-mail: juan.berner@nhs.net).

(-Fig. 2). This technique also helps preserve the suprafascial vascular plexus on the flap side, which may reduce fat necrosis. The particular way of retracting presented in this technical note allows adequate visualization of the right areolar plane facilitating identification and dissection of vascular perforators ( - Video 1 ). In the context of pressures for increasing operating efficiency, ${ }^{3}$ the authors advocate using every single tool at hand to facilitate this task.

\section{Video 1}

Video showing how effective retraction, pulling the flap away from the surgeon can reveal a clear and safe areolar plane. Online content including video sequences viewable at: www.thieme-connect.com/products/ejournals/ html/10.1055/s-0039-3402356.
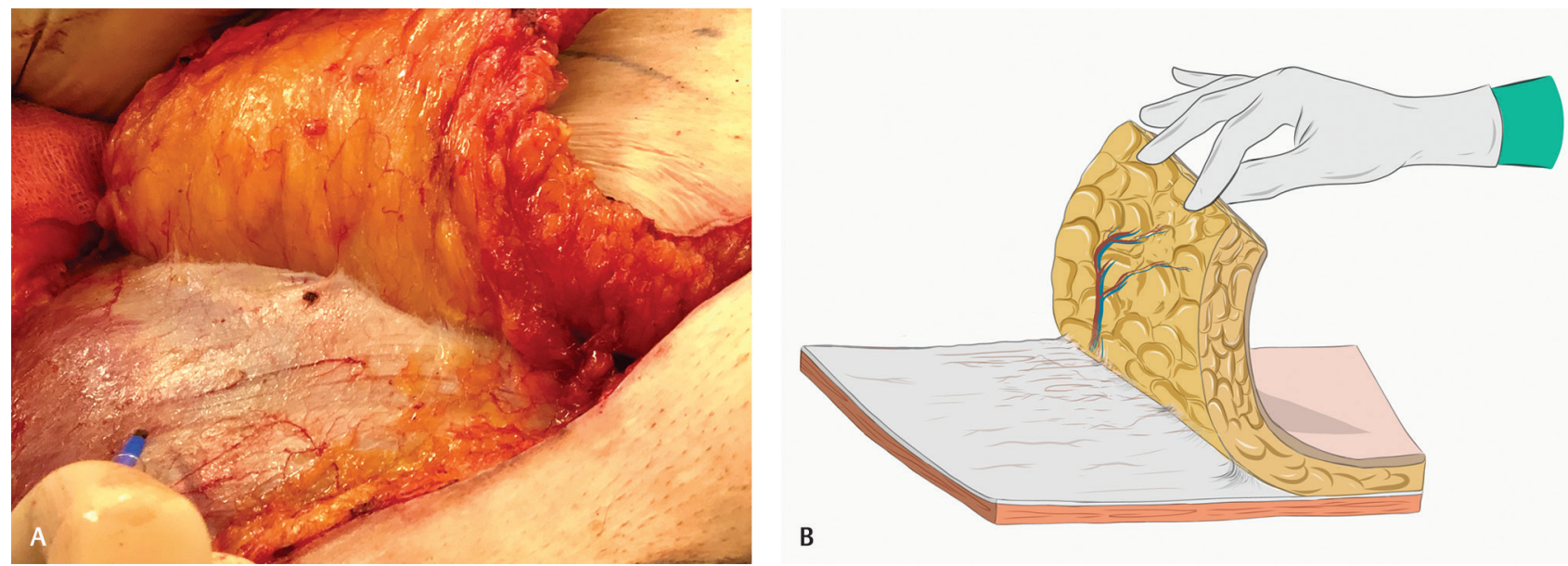

Fig. 1 (A, B) Standard upward retraction provides countertraction but does not optimize visualization of perforators.

received

October 25, 2019

accepted after revision

November 1, 2019

published online

December 26, 2019
DOI https://doi.org/

10.1055/s-0039-3402356

ISSN 0970-0358.
(C)2019 Association of Plastic

Surgeons of India
License terms

(ㄷ) (1) $\ominus \circledast$ 

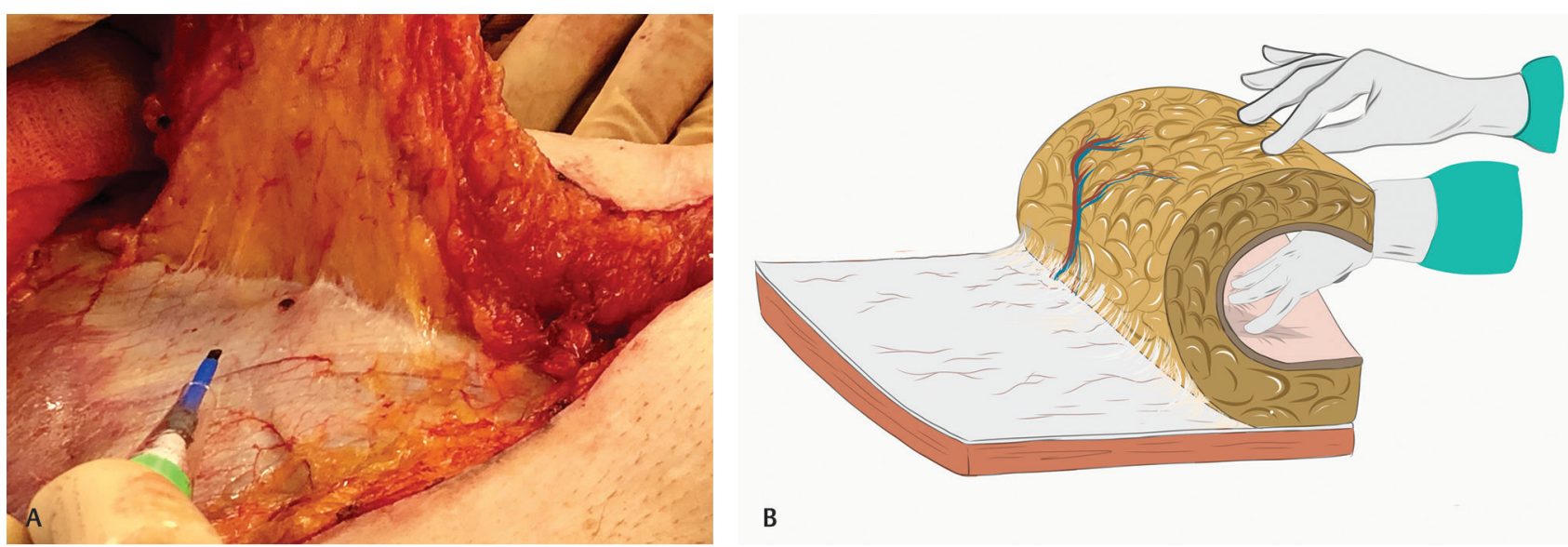

Fig. 2 (A, B) While the flap is held up between the index and thumb, the other fingers are used to retract away from the surgeon. This helps "tent" the flap revealing a plane of loose areolar tissue which is easier to dissect and allows better visualization of perforators.

\section{Conflict of Interest}

None declared.

\section{Declaration}

This technical tip was presented at the World Society of Reconstructive Microsurgery in Bologna, Italy 12th to 15th June, 2019.

\section{References}

1 Koshima I, Yamamoto T, Narushima M, Mihara M, Iida T. Perforator flaps and supermicrosurgery. Clin Plast Surg 2010;37(4):683-689, vii-iii
2 Steele PRC, Curran JF, Mountain RE. Current and future practices in surgical retraction. Surgeon 2013;11(6):330-337

3 Marsh D, Patel NG, Rozen WM, Chowdhry M, Sharma H, Ramakrishnan VV. Three routine free flaps per day in a single operating theatre: principles of a process mapping approach to improving surgical efficiency. Gland Surg 2016;5(2):107-114 
